Article

\title{
Feature Selection of Time Series MODIS Data for Early Crop Classification Using Random Forest: A Case Study in Kansas, USA
}

\author{
Pengyu Hao ${ }^{1,2}$, Yulin Zhan ${ }^{1, *}$, Li Wang ${ }^{1}$, Zheng Niu ${ }^{1}$ and Muhammad Shakir ${ }^{1}$
}

1 The State Key Laboratory of Remote Sensing Science, Institute of Remote Sensing and Digital Earth, Chinese Academy of Sciences, Beijing 100101, China; E-Mails: haopy@radi.ac.cn (P.H.); wangli@radi.ac.cn (L.W.); niuzheng@radi.ac.cn (Z.N.); mshakirgeo@gmail.com (M.S.)

2 University of Chinese Academy of Sciences, Beijing 100049, China

* Author to whom correspondence should be addressed; E-Mail: zhanyl@radi.ac.cn; Tel.: +86-136-9159-6156.

Academic Editors: Tao Cheng, Zhengwei Yang, Yoshio Inoue, Yan Zhu, Weixing Cao and Prasad S. Thenkabail

Received: 29 January 2015 / Accepted: 22 April 2015 / Published: 28 April 2015

\begin{abstract}
Currently, accurate information on crop area coverage is vital for food security and industry, and there is strong demand for timely crop mapping. In this study, we used MODIS time series data to investigate the effect of the time series length on crop mapping. Eight time series with different lengths (ranging from one month to eight months) were tested. For each time series, we first used the Random Forest (RF) algorithm to calculate the importance score for all features (including multi-spectral data, Normalized Difference Vegetation Index (NDVI), Normalized Difference Water Index (NDWI), and phenological metrics). Subsequently, an extension of the Jeffries-Matusita (JM) distance was used to measure class separability for each time series. Finally, the RF algorithm was used to classify crop types, and the classification accuracy and certainty were used to analyze the influence of the time series length and the number of features on classification performance; the features were added one by one based on their importance scores. Results indicated that when the time series was longer than five months, the top ten features remained stable. These features were mainly in July and August. In addition, the NDVI features contributed the majority of the most significant features for crop mapping. The NDWI and data from multi-spectral bands also contributed to improving crop mapping. On the other hand, separability, classification accuracy, and certainty increased with the number of features
\end{abstract}


used and the time series length, although these values quickly reached saturation. Five months was the optimal time series length, as longer time series provided no further improvement in the classification performance. This result shows that relatively short time series have the potential to identify crops accurately, which allows for early crop mapping over large areas.

Keywords: time series length; MODIS; feature selection; Random Forest; classification certainty

\section{Introduction}

Crop-type information is important for food security, and the demand for accurate crop maps is increasing in society and in the plant industry [1-3]. In addition, crop maps can be incorporated into a range of environmental models to improve understanding of the overall agricultural response to environmental issues $[4,5]$. Remote sensing data have shown potential for mapping crop distributions at both regional and local scales [4,6,7], and substantial efforts have been made toward monitoring agricultural land and accurately assessing crop acreage $[8,9]$.

Multi-temporal remote sensing data can be used to describe the vegetation conditions over different periods, and have been widely employed to produce crop distribution maps [10-13]. Images of several key periods, such as the "initial spring green-up phase" and the "late senescence phase" are sufficient for accurate crop mapping [14-16]. In addition, Hao et al. [17] merged Landsat and Huan Jing (HJ) data, which have similar spatial resolution to Landsat and higher temporal resolution, to obtain an image time series with relatively high temporal resolution, and increase the possibility of acquiring images in the optimal periods for crop identification. The timeline is an important consideration for crop classification because obtaining an early classification result benefits both decision makers and the private sector [18]. Zhou et al. [19] found that reducing the time series length had little influence on the average accuracy of land cover classification, except for a slight increase in the classification variance when different training samples were used. However, few studies have determined the effect of time series length on crop-type mapping.

Apart from multi-spectral time series data, several vegetation indices (VIs) and phenological metrics derived from VI time series have been used to enrich the information available for vegetation mapping and monitoring [20-23]. However, using all these features involves a large volume of data, which may increase computation times with little improvement in accuracy [24]. To solve the problems associated with large volumes of data, various feature selection methods have been employed [4,24-26]. Most previous studies have focused on the effects of feature-space size reduction on classification accuracy and certainty, but the contributions of different features remain unclear.

The majority of the statistical measures used to assess land-cover classification accuracy are based on the confusion matrix [27]. The information contained in this matrix is a location-independent pattern of misclassification, which can only provide a generally accurate measurement for the user [26]. Classification certainty can be defined as a quantitative measure of doubt regarding a specific single class assignment [28]. Additionally, several newly proposed classifiers, such as Support Vector 
Machine (SVM), Random Forest (RF), and C5.0, provide a soft output (a probability for each class), and this information is used to derive the certainty for each pixel $[4,29,30]$. In contrast to accuracy measures, pixel-based certainty measures allow spatial representation of the map quality, and provide a better understanding of location error in classification [24,26].

The objectives of this research were to use the MODIS reflectance product on a regional scale to analyze (1) the effect of time series lengths on crop classification, (2) the importance of multi-spectral band data and indices (NDVI and NDWI) at different time series lengths, and (3) the influence of the number of features on crop identification. The cropland data layer (CDL) data at a spatial resolution of $30 \mathrm{~m}$ was used as ground reference data [31]. In addition, both classification accuracy and certainty were utilized to better understand the quality of the crop mapping.

\section{Study Area and Datasets}

\subsection{Study Area}

This study was conducted in the State of Kansas $\left(37^{\circ} \mathrm{N}-40^{\circ} \mathrm{N}, 94^{\circ} \mathrm{W}-102^{\circ} \mathrm{W}\right)$ in the U.S. Central Great Plains (Figure 1). Kansas is a state dominated by agriculture with $46.9 \%$ (10.0 million ha) of its total area dedicated to crop production [32]. The major crop types are alfalfa, corn, sorghum, soybeans, and winter wheat [33]. Although each crop has a well-defined crop calendar and unique seasonal growth pattern, the growth situation varies throughout the state. On one hand, the state has a significant east-west precipitation gradient that has a strong influence on crop growth. For example, western Kansas receives on average $460-510 \mathrm{~mm}$ of precipitation per year, whereas eastern Kansas receives 890-1020 mm [16]. Therefore, eastern Kansas receives adequate precipitation, and corn and soybeans are the two primary crops grown in this part of the state. However, semiarid western Kansas commonly experiences drought events; as a result, drought-tolerant crops, such as winter wheat and sorghum, are widely planted. In addition, water-requiring crops, such as alfalfa, corn, and soybean require irrigation from aquifers. Another complicating factor is that planting times for many crops in Kansas differ by more than one month "along a general southeast (earliest) to northwest (latest)" trend [34]. For example, the recommended planting date for corn is 25 March to 25 April for southeast Kansas, but 20 April to 20 May for northwest Kansas. Moreover, the size of fields varies across the state. According to [32], western Kansas has "large individual fields (sizes commonly range from 65 to 245 ha)" while the fields in eastern Kansas are small (less than 65 ha) and the cropland areas are fragmented.

\subsection{MODIS Data and Derived Phenological Variables}

A 30-date time series of 8-day composite MODIS 500-m reflectance data (MOD09A1), spanning 7 April to 25 November, 2013 was created for Kansas. Data were required from four MODIS tiles (h09v04, h09v05, h10v04, and h10v05) for statewide coverage. The tiled MODIS data were acquired from the Land Processes Distributed Active Archive Center (LP-DAAC) [35], reprojected from the Sinusoidal to UTM projection (WGS 84 zone 14N), and subset over Kansas for each composite period and then sequentially stacked to produce the time series dataset. Two additional indices, the Normalized Difference Vegetation Index (NDVI) and the Normalized Difference Water Index (NDWI), were derived from the time series of MODIS reflectance data using Equations (1) and (2) [36]: 


$$
\begin{aligned}
& \text { NDVI }=\frac{\rho(B 2)-\rho(B 1)}{\rho(B 2)+\rho(B 1)} \\
& \text { NDWI }=\frac{\rho(B 2)-\rho(B 5)}{\rho(B 2)+\rho(B 5)}
\end{aligned}
$$

where $\rho$ (B1), $\rho$ (B2), and $\rho$ (B5)are the reflectance values of MODIS bands 1,2 , and 5 , respectively. Each variable has the same length as the MODIS reflectance time series.

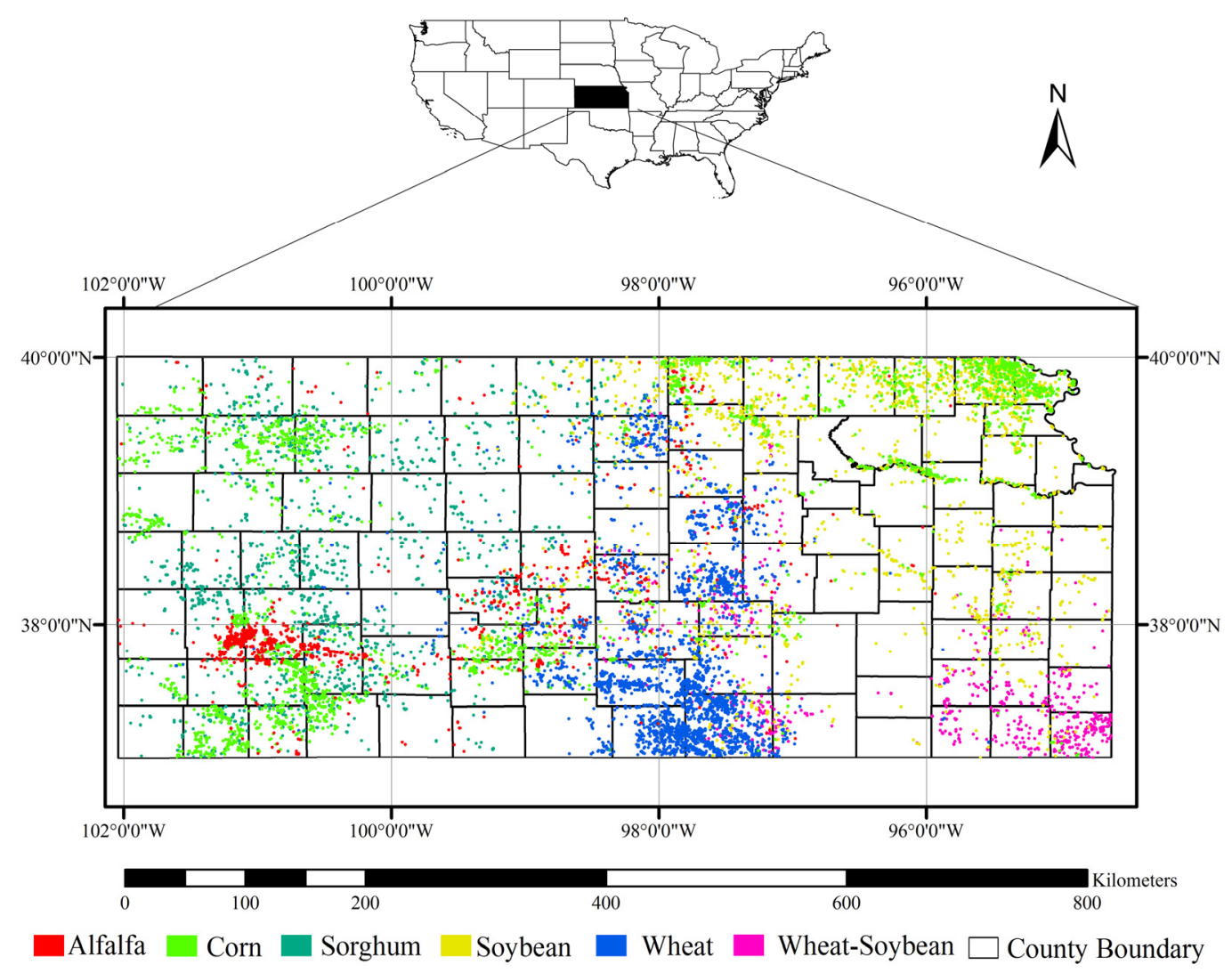

Figure 1. Study area and distribution of ground reference samples.

Land surface phenological metrics represent stages of plant growth or development that occurs during a growing season, and several phenological characters can be identified using multi-temporal remote sensing data [37]. In this research, nine unique annual phenology metrics were employed for crop classification. The metrics included start-of-season time (SOST), start-of-season NDVI (SOSN), end-of-season time (EOST), end-of-season NDVI (EOSN), maximum NDVI (MaxN), maximum NDVI time (MAXT), duration of season (DOS), amplitude of NDVI (AON), and seasonal time-integrated NDVI (TIN) [38]. These metrics were derived from250-m weekly eMODIS NDVI using a curve derivative method [4]. This method employed a delayed moving average (DMA), in which predicted values were based on previous observations along a time-series NDVI curve. Smoothed NDVI data values were compared to a moving average of the previous observations to identify departures from an established trend. For example, if smoothed NDVI values became larger than those predicted by the DMA, this departure point was labeled as the start of the growing season (SOS) [38]. All available annual 250-m phenology metrics for 2013 were obtained from [38] and then resampled to a spatial resolution of 500-m [38]. The variables used in this research are shown in Table 1. 
Table 1. Groups of input variables for classification. Notes: The wavelengths of the reflectance bands are $c .620-670 \mathrm{~nm}$ (B1), c. 841-876 nm (B2), c. 459-479 nm (B3), c. 545-565 nm (B4), c. 1230-1250 nm (B5), c. 1628-1652 nm (B6), and c. 2105-2155 nm (B7).

\begin{tabular}{ccc}
\hline Group Name & $\begin{array}{c}\text { Number of Variables } \\
\text { in the Group }\end{array}$ & Denotation of Variables \\
\hline Reflectance & $210(30$ images $\times 7$ bands $)$ & BxDy, $\mathrm{x}=1,2, \ldots 7, \mathrm{y}=1,2, \ldots 30$ \\
Indices (NDVI and NDWI $)$ & $60(30$ image $\times 2$ bands $)$ & NDVI_Dy, NDWI_Dy, $\mathrm{y}=1,2, \ldots 30$ \\
Phenological metrics & 9 & SOST, SOSN, EOST, EOSN, MaxN, MaxT, DOS, AON, TIN \\
\hline
\end{tabular}

\subsection{Reference Dataset}

The crop-type reference data used in this study were obtained from the National Agricultural Statistics Service (NASS) Cropland Data Layers (CDL) for 2013 [31]. Table 2 shows the classification accuracy of CDL in Kansas ordered by areal proportion. The bold-font crops were selected as reference crops in this study because both producer's and user's accuracies were higher than $85 \%$, and the areal proportions of these crops were more than $1 \%$ [39]. To obtain pure pixels on 500-m spatial resolution MODIS images, we first obtained the MODIS pixel grid from the MODIS image and then calculated the fraction for every crop in each MODIS pixel using CDL data. If one crop filled more than $80 \%$ of a MODIS pixel, we defined that pixel as a "pure" pixel and used it as a reference pixel. In this procedure, we selected $80 \%$ as the threshold because it provided a balance between pixel quality and sample number. A higher threshold (such as 90\%) might increase the purity of the pixel, but the sample number would drop substantially because the spatial resolution was 500-m in this study. Conversely, a lower threshold (such as $70 \%$ ) could increase the pixel number, but would lead to more sample pixels of low purity. We then extracted the time series quality assessment of the MODIS 500-m reflectance product using the reference pixels. If there were more than 25 "corrected products produced at ideal quality in all bands" periods in a reference pixel [40], the pixel was retained. Otherwise, the pixel was removed from the reference dataset. For the remaining pixels, the reflectance for low-quality periods (if the quality of a pixel is not 'ideal quality', we define it as 'low-quality') was replaced by the average reflectance of the previous and following periods. Subsequently, the reference pixels were randomly divided into two parts: training samples and validation samples. The numbers of these samples are shown in Table 3, and their distributions are shown in Figure 1.

Table 2. 2013 Kansas cropland data layer statewide agricultural accuracy.

\begin{tabular}{ccccc}
\hline Crop Type & CDL Code & Producer's Accuracy & User's Accuracy & Areal Proportions \\
\hline Winter Wheat & 24 & $94.37 \%$ & $94.45 \%$ & $38.33 \%$ \\
Corn & 1 & $93.21 \%$ & $93.6 \%$ & $16.99 \%$ \\
Soybeans & 5 & $92.97 \%$ & $92.97 \%$ & $13.66 \%$ \\
Sorghum & 4 & $89.32 \%$ & $89.27 \%$ & $11.25 \%$ \\
Fallow/Idle Cropland & 61 & $87.47 \%$ & $87.81 \%$ & $11.02 \%$ \\
(Double Crop) Winter & 26 & $85.9 \%$ & $85.25 \%$ & $3.00 \%$ \\
$\quad$ Wheat/Soybeans & & $56.07 \%$ & $90.39 \%$ & $2.85 \%$ \\
Other Hay/Non Alfalfa & 37 & $85.95 \%$ & $91.21 \%$ & $1.95 \%$ \\
$\quad$ Alfalfa & 36 & & &
\end{tabular}


Table 2. Cont.

\begin{tabular}{ccccc}
\hline Crop Type & CDL Code & Producer's Accuracy & User's Accuracy & Areal Proportions \\
\hline $\begin{array}{c}\text { (Double Crop) Winter } \\
\text { Wheat/Sorghum }\end{array}$ & 236 & $36.64 \%$ & $65.03 \%$ & $0.37 \%$ \\
Canola & 31 & $78.22 \%$ & $90.75 \%$ & $0.12 \%$ \\
Rye & 27 & $37.55 \%$ & $76.76 \%$ & $0.11 \%$ \\
Oats & 28 & $37.63 \%$ & $72.27 \%$ & $0.10 \%$ \\
\hline
\end{tabular}

Table 3. Number of training and validation samples.

\begin{tabular}{ccc}
\hline Crop Type & Training & Validation \\
\hline Alfalfa & 562 & 561 \\
Corn & 1441 & 1441 \\
Sorghum & 847 & 847 \\
Soybean & 1005 & 1006 \\
Wheat & 1665 & 1664 \\
Wheat-soybean & 437 & 437 \\
Total & 5957 & 5956 \\
\hline
\end{tabular}

\section{Method}

The overall methodology used in this study is presented in Figure 2. First, we extracted time series multi-spectral band data and indices (NDVI and NDWI) from the MOD09 product and phenological metrics from eMODIS phenological data using the ground reference data. We then exploited the Random Forest (RF) algorithm to calculate an importance score for all available features containing multi-spectral, NDVI, NDWI, and phenological metrics for each time series length using the training samples. To simplify the analysis, we used one month as the unit of the time-series period (Table A1 in Appendix). Therefore, the time series length varied from one month to eight months. Then, an extension of the Jeffries-Matusita (JM) distance was used to calculate the separability among all crops. Furthermore, the RF algorithm was used to classify crop types and obtain a probability output for each crop. The classification accuracy and certainty were then obtained to measure the classification performance. When calculating the extension of the JM distance and classifying crop types, features were added one by one based on the importance score acquired from the RF algorithm for each time series length.

\subsection{Random Forest}

The classification algorithm employed for this research was the Random Forest (RF) algorithm. The $\mathrm{RF}$ algorithm is an ensemble machine learning technique that combines multiple trees [30]. Each tree is constructed using two-thirds of the original cases. Then, the remaining one-third of cases is employed to generate a test classification, with an error referred to as the "out-of-bag error" (OOB error). Subsequently, the model output is determined by the majority vote of the classifier ensemble [26]. Two free parameters can be optimized in the RF algorithm: the number of trees (ntree) and the number of features to split the nodes (mtry). The advantages of the RF algorithm, such as the relatively high efficiency with large datasets, the probability output for each class, and the generated OOB error (an 
internal unbiased estimate of the generalization error) make it suitable for remote sensing applications [41]. In this research, both the feature importance score and crop classification were obtained using the RandomForest package for R [42]. The ntree parameter was set to a relatively high value of 1000 to allow convergence of the OOB error statistic, and mtry was set to the square root of the total number of input features [43]. Additionally, the decreased accuracy (i.e., the difference in prediction accuracy before and after permutation of the variable of interest)was used to measure the importance of the features. As for classification, the RF algorithm allowed quantification of the prediction probability at the pixel level, together with the class label. The probability $\mathrm{p}(\mathrm{i})$ of a pixel being classified as class i was defined as

$$
\mathrm{p}(\mathrm{i})=\frac{\mathrm{k}_{\mathrm{i}}}{\mathrm{k}}
$$

where $\mathrm{k}$ was the total number of trees involved in the classification process, and $\mathrm{k}_{\mathrm{i}}$ was the number of trees classifying the pixel as cover type i [26].

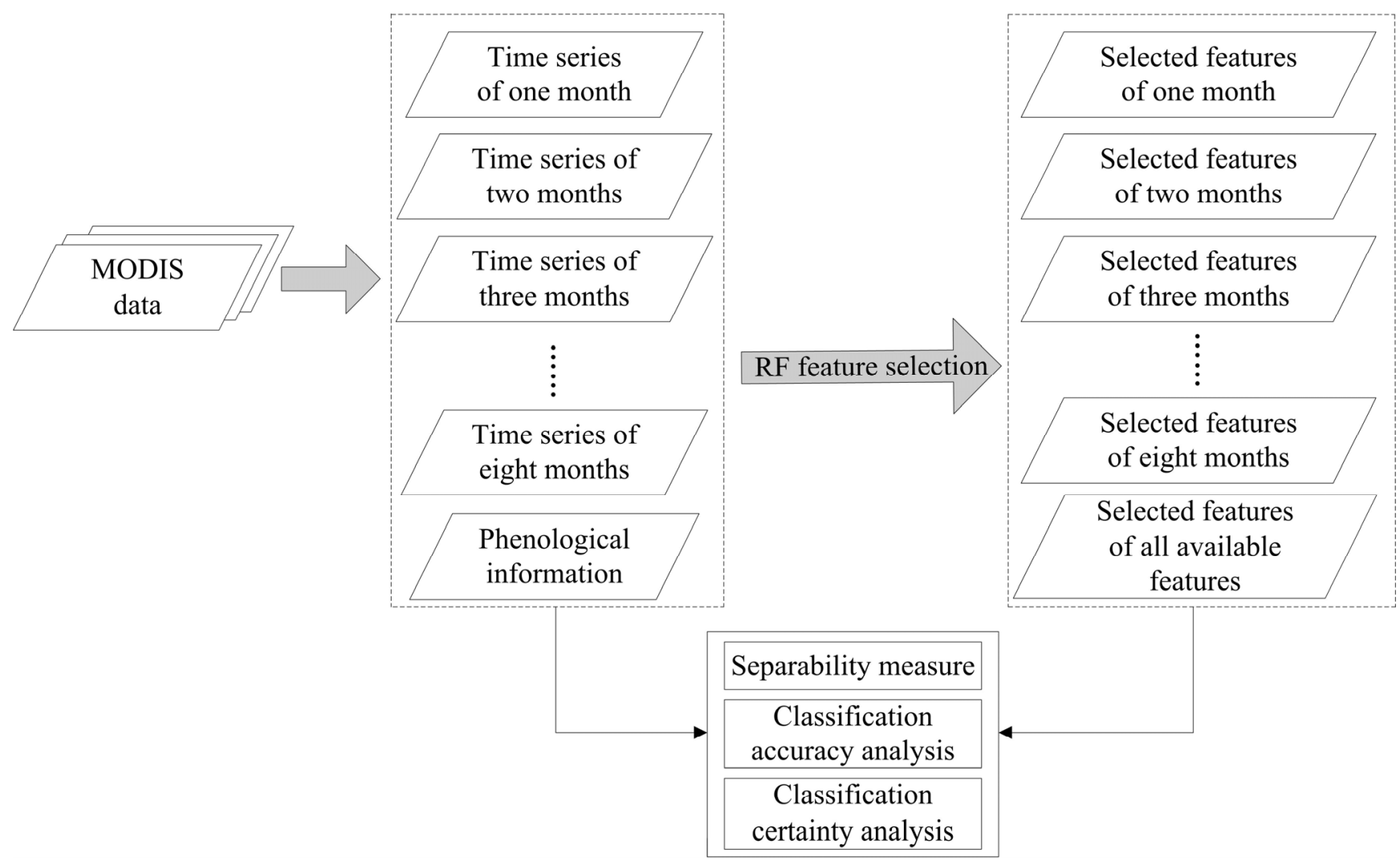

Figure 2. Methodology used in this study.

\subsection{Extension of the Jeffries-Matusita Distance}

In this study, we used the JM distance to measure the separability for each pair of crops, because previous research had shown that JM distance can provide a more accurate separability indicator than other distance measures, such as Euclidean distance or divergence [14,44]. The JM distance between a pair of class-specific functions was given by:

$$
\operatorname{JM}\left(c_{i}, c_{j}\right)=\int_{x}\left(\sqrt{p\left(x \mid c_{i}\right)}-\sqrt{p\left(x \mid c_{j}\right)}\right)^{2} d x
$$


where $x$ denoted a span of VI time series values, and $c_{i}$ and $c_{j}$ (lowercase $c$ ) denoted the two crop classes under consideration. Under normality assumptions, Equation (4) was reduced to $M=2\left(1-\mathrm{e}^{-\mathrm{B}}\right)$, where

$$
\mathrm{B}=\frac{1}{8}\left(\mu_{\mathrm{i}}-\mu_{\mathrm{j}}\right)^{\mathrm{T}}\left(\frac{\mathrm{C}_{\mathrm{i}}+\mathrm{C}_{\mathrm{j}}}{2}\right)^{-1}\left(\mu_{\mathrm{i}}-\mu_{\mathrm{j}}\right)+\frac{1}{2} \ln \left(\left|\frac{\left|\mathrm{C}_{\mathrm{i}}+\mathrm{C}_{\mathrm{j}}\right|}{2 \sqrt{\left|\mathrm{C}_{\mathrm{i}}\right| \times\left|\mathrm{C}_{\mathrm{j}}\right|}}\right|\right)
$$

and $\mathrm{C}_{\mathrm{i}}$ and $\mathrm{C}_{\mathrm{j}}$ (uppercase $\mathrm{C}$ ) were the covariance matrices of classes $\mathrm{i}$ and $\mathrm{j}$, respectively. Additionally, $\left|C_{i}\right|$ and $\left|C_{j}\right|$ were the determinants of $C_{i}$ and $C_{j}$, respectively. The JM distance ranged from 0 to 2 , with a high value indicating a high level of separability between the two classes [45].

When considering the separability of multiple classes, different classes were given different weights to account for the different sample sizes of each class. The extension of the JM distance $\left(\mathrm{J}_{\mathrm{Bh}}\right)$ was used for this purpose. $\mathrm{J}_{\mathrm{Bh}}$ was calculated from Equation (6) based on Bhattacharyya bounds, and it gave greater importance to classes with high a priori probabilities in the selection process [46]:

$$
\mathrm{J}_{\mathrm{Bh}}=\sum_{\mathrm{i}=1}^{\mathrm{N}} \sum_{\mathrm{j}>\mathrm{i}}^{\mathrm{N}} \sqrt{\mathrm{p}\left(\mathrm{w}_{\mathrm{i}}\right) \times \mathrm{p}\left(\mathrm{w}_{\mathrm{j}}\right)} \times \mathrm{JM}^{2}(\mathrm{i}, \mathrm{j})
$$

where $\mathrm{N}$ was the number of classes, and $\mathrm{p}\left(\mathrm{w}_{\mathrm{i}}\right)$ and $\mathrm{p}\left(\mathrm{w}_{\mathrm{j}}\right)$ were the a priori probabilities of classes $\mathrm{i}$ and $\mathrm{j}$, respectively, which were calculated using the combination of training samples in Table 3.

\subsection{Accuracy and Certainty Measures}

A series of accuracy metrics were employed to evaluate the classification accuracy. First, overall accuracy (OA), producer's accuracy (PA), and user's accuracy (UA) were used for the hard results (class labels) [27]. For the probability result, a soft answer was provided by the random forest algorithm in the form of a vector containing probability estimates belonging to each class:

$$
\mathrm{p}(\mathrm{x})=\left\{\mathrm{p}_{1}(\mathrm{x}), \cdots, \mathrm{p}_{\mathrm{k}}(\mathrm{x}), \cdots, \mathrm{p}_{\mathrm{K}}(\mathrm{x}), \mathrm{k}=1,2, \cdots, \mathrm{K}\right\}
$$

where $p_{k}(x)$ was the probability that $x$ belongs to class $k$, and $\mathrm{K}$ was the number of classes. In this study, the probability vector was first sorted in descending order. Then, we used the specificity measure to calculate the certainty, as in Equation (8) [47]:

$$
\mathrm{C}(\mathrm{x})=\sum_{\mathrm{k}=1}^{\mathrm{K}-1}\left(\hat{\mathrm{p}}_{\mathrm{k}}(\mathrm{x})-\hat{\mathrm{p}}_{\mathrm{k}+1}(\mathrm{x})\right)
$$

The advantage of the specificity measure is that it applies all the information in the probability vector. The certainty of a pixel is equal to 1 if the maximum probability in its probability vector is 1 . On the other hand, if the all the classes have the same probability $\left(\hat{\mathrm{p}}_{\mathrm{k}}(\mathrm{x})=1 / \mathrm{K}\right)$, the certainty of the pixel is 0 .

\section{Results}

\subsection{Importance of Features for Crop Mapping}

An analysis of the ten most informative features for each time series length was shown in Figure 3. The selected features varied among the different time series lengths. During April and May (Figure 3a,b), the most important features were mainly multi-spectral bands data. However, the selection of these features may not have a phenological component because most summer crops were immature, 
and the standard deviations of the importance scores from 20 model runs were relatively high (higher than 1.5 in most cases). NDVI and NDWI were selected when the time series length was longer than three months (Figure 3c). In Figure 3d,e, the time series lengths were one month longer than in Figure $3 \mathrm{c}, \mathrm{d}$, and several features unique to the additional months (such as the features in July for Figure $3 \mathrm{~d}$ and August for Figure 3e) were selected as the most important features. However, in Figure $3 \mathrm{f}-\mathrm{h}$, the time series were longer than five months, but no features from the extra months were found to be among the most important.
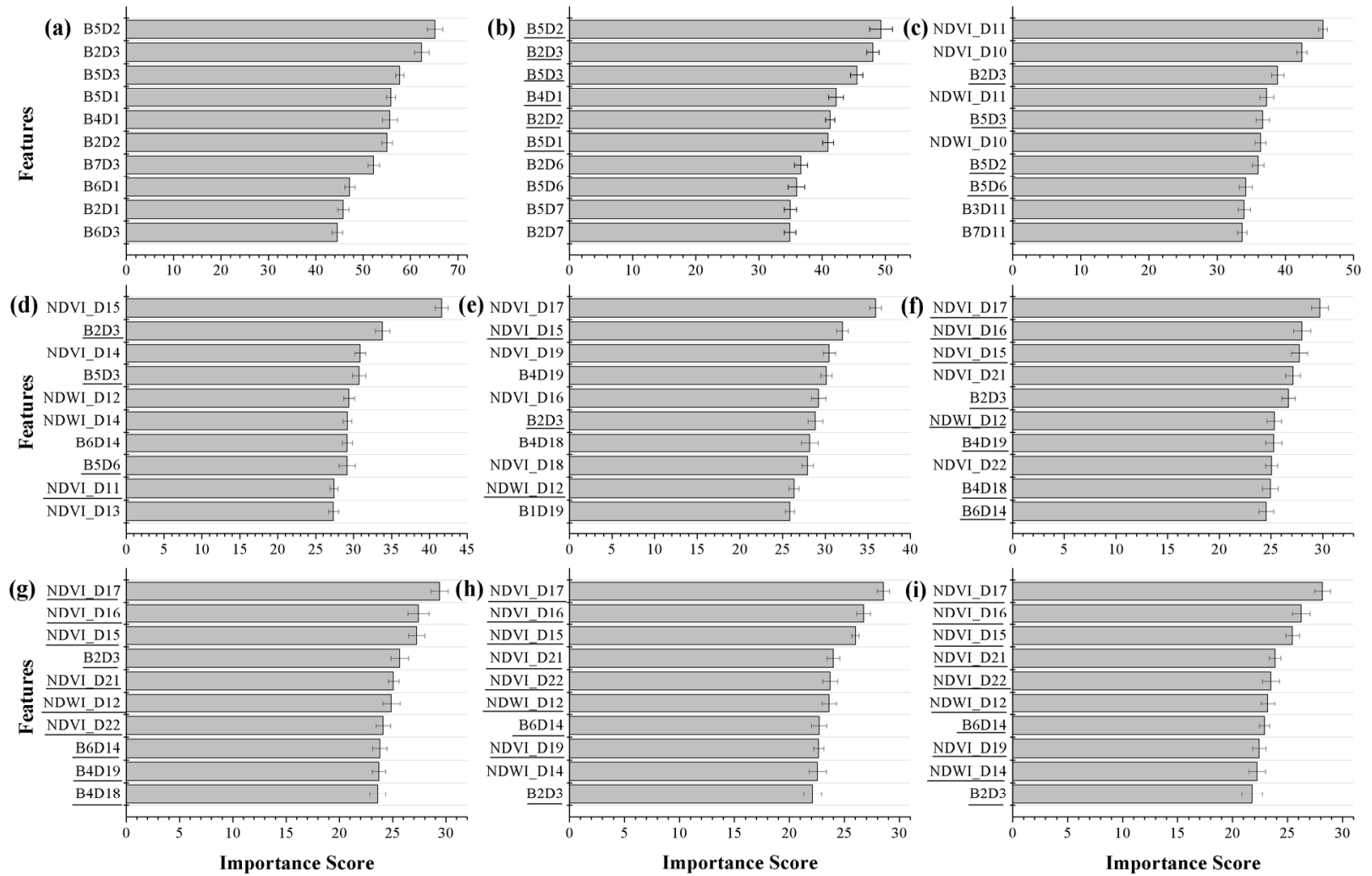

Figure 3. Mean relative feature importance of the ten most important features for each time series length. Error bars indicate the standard deviation of the variable score for 20 model runs. In addition, "B1-B7" in the feature names indicates the number of the MODIS band; "D1-D30"" indicates the acquisition date: (a) D1-D3 in April, (b) D1-D7 for April to May, (c) D1-D11 for April to June, (d) D1-D15 for April to July, (e) D1-D19 for April to August, (f) D1-D22 for April to September, (g) D1-D26 for April to October, (h) D1-D30 for April to November, and (i) D1-D30 and phenological metrics. The underlined features indicate that these features were among the ten most important features in the previous shorter time series.

When both NDVI and NDWI were selected in the top ten features, NDVI obtained a higher importance score than NDWI (Figure 3c); moreover, when the time series was longer than five months, more NDVI features were selected for the top ten important features. Furthermore, the phenological features were not among the features selected as most important when combining phenological information with multi-spectral metrics, vegetation indices, and water indices metrics (Figure 3i).

The importance score of the selected features decreased with the augmentation of the time series length. Figure 3a showed that the importance scores of the most important features were nearly 60, but 
the scores were around 20 for the most important features selected from the eight-month time series (Figure 3h). This was because the importance score was measured by the difference in prediction accuracy before and after permutations of the feature. Therefore, the importance score reduced when more features were employed to build the RF model.

\subsection{Class Separability}

Month-by-month JM distances in Kansas are shown in Figure 4, and the time series for different crops are shown in Figure 5. Winter wheat was highly separable from the summer crops (JM distance larger than 1.5). During the early growing season (April and May), wheat had a relatively high vegetation fraction but the summer crops had not yet been sown. Then, in summer (July and August), the wheat had been harvested and the summer crops had developed (Figure 5). In October and November, wheat was sown again and the summer crops were harvested. As for winter wheat and the double crop wheat-soybean, the JM distance was high (larger than 1.5) in August because the soybean had developed during this period. Among the three summer crops, sorghum and soybean had high separability in June (JM distance larger than 1.5) and September because of their different rates of emergence and senescence. Corn was highly separable from sorghum because of its earlier planting and emergence (corn is mostly sown in May and emerges in early June, whereas sorghum is planted in June). Additionally, the JM distance between corn and soybean was lower than 1.0 throughout the growing season because of the similar planting, reproduction, and harvest periods (Figure 5). Alfalfa had a relatively high JM distance (larger than 1.2) from the other crops throughout almost the entire growing season, except when compared with several summer crops, such as corn, sorghum, and soybean, during June and August (JM distance around 1). The relatively low separability in this period was mainly because of the fact that the summer crops had developed and the separability between alfalfa and these summer crops was relatively low (Figure 5). At the beginning of the growing season (during April and May), soybean was the least separable crop compared to alfalfa; this result is unexpected because alfalfa and wheat are well developed during this time, whereas soybean is not developed [16]. Thus, soybean should have a better separability than wheat. There are two possible explanations for this unexpected outcome: (1) the misclassification of CDL data in Kansas and (2) the use of mixed pixels as training samples. Firstly, the producer's accuracy for alfalfa was $85.95 \%$ (Table 1), which indicated that several other crops were mislabeled as alfalfa. Additionally, the average NDVI of alfalfa in this period was substantially lower than values found in [16]. On the other hand, the misclassification also led to the relatively high standard deviation of alfalfa NDVI profiles (Figure 5). As for the second reason, both alfalfa and soybean had relatively small field sizes, which resulted in more mixed pixels with higher NDVI profile variations (standard deviations larger than 0.1 ). Thus, the lower alfalfa NDVI and the higher standard deviation of the two crops contributed to the unexpected low separability between alfalfa and soybean during April and May.

Figure 6 showed the relationship between the JM distance of crop pair comparisons and the time series length. The figure showed that the JM distance increased with the time series length. For example, alfalfa had a relatively high JM distance when the time series was two months, and the JM distances between alfalfa and other crops then increased until the time series reached five months (when JM distances were 2). For winter wheat, when the time series length was three months, the JM distance 
between wheat and other summer crops was almost 2. In addition, the JM distance among the three summer crops increased substantial when the time series length was shorter than four months. Beyond four months, further increases in the time series did not meaningfully increase the JM distance. However, the JM distance between corn and soybean was still low (lower than 1). Furthermore, wheat and wheat-soybean demonstrated good separability when the time series length was longer than five months.
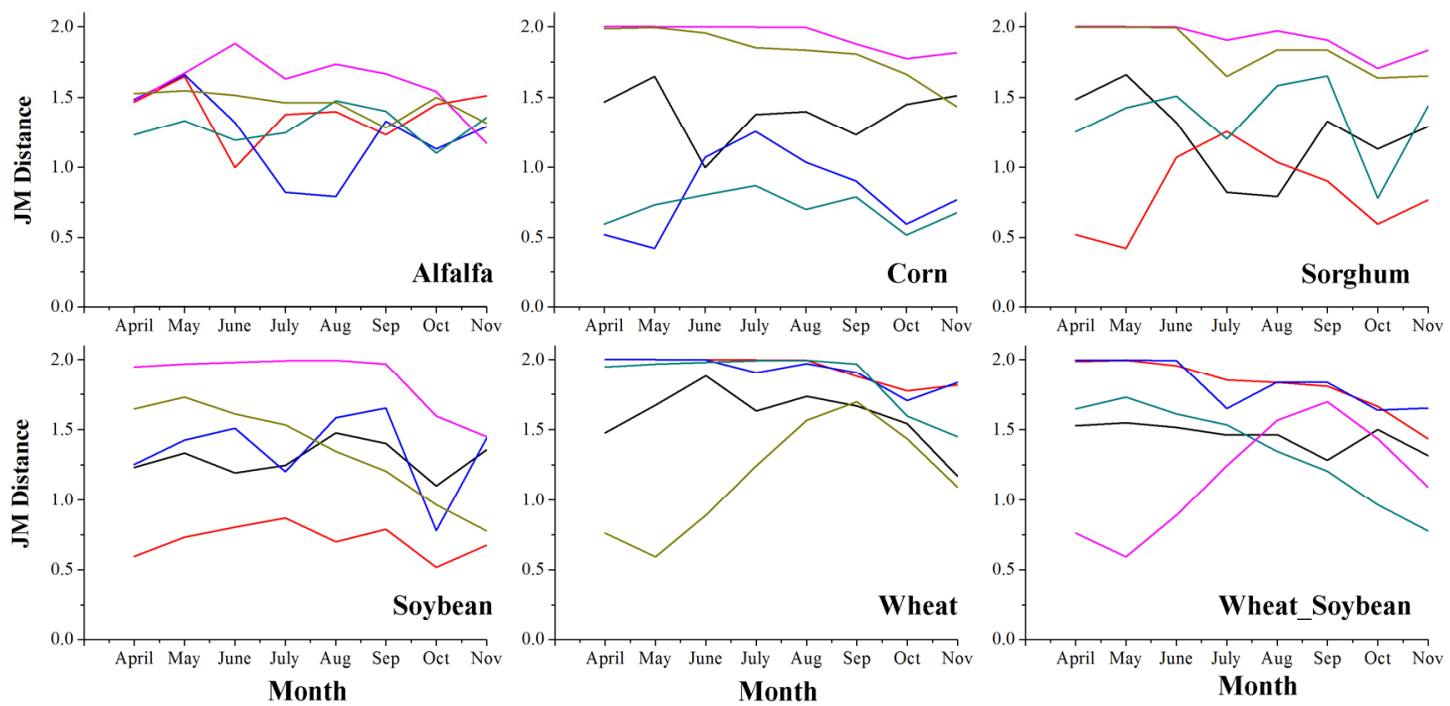

Figure 4. JM distance values for all crop pair comparisons in each month using training samples from Kansas.

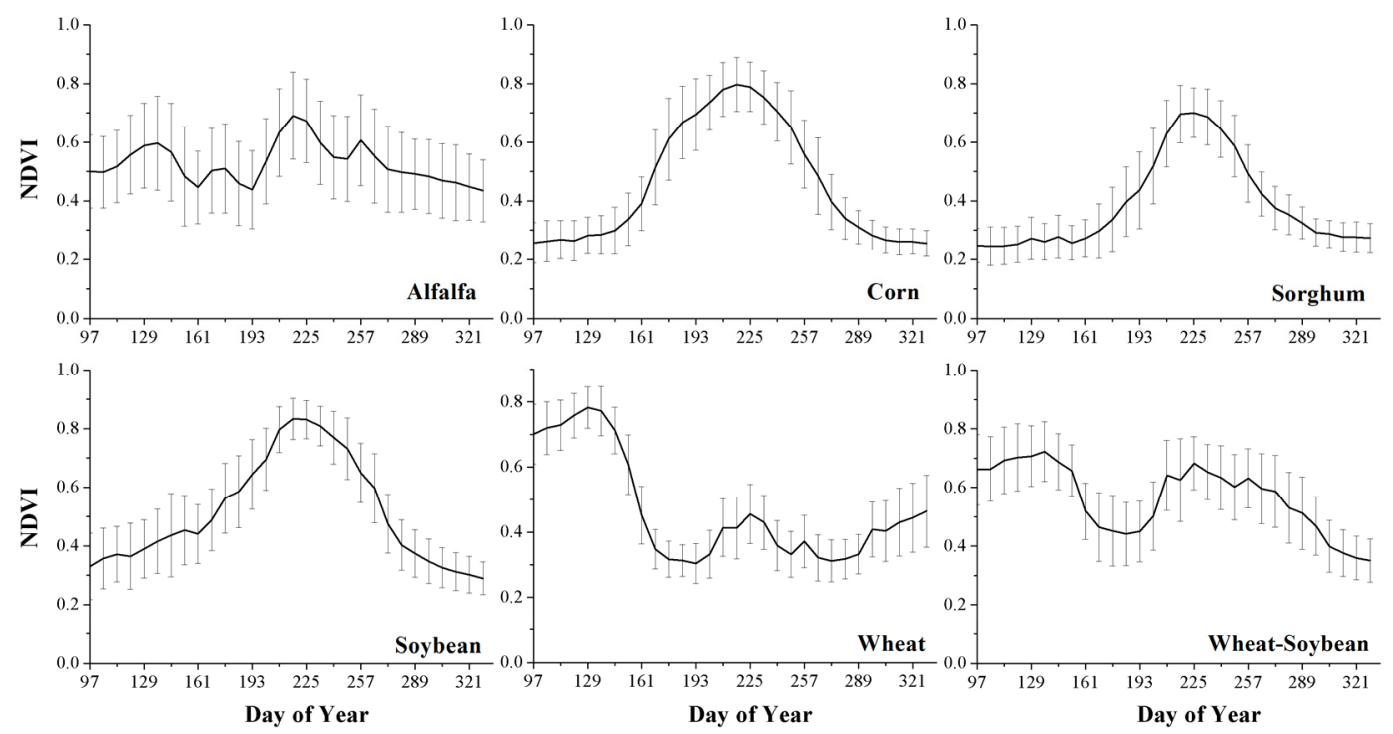

Figure 5. Average NDVI time series for the crops used in this study. Error bars indicate the standard deviation of the NDVI of the samples.

Figure 7 showed the relationship between the number of features used and $\mathrm{J}_{\mathrm{BH}}$ (extension of the JM) distance. The maximum $\mathrm{J}_{\mathrm{BH}}$ increased substantially when the time series length was shorter than five months (April-August). For example, the maximum $\mathrm{J}_{\mathrm{BH}}$ was 5.67 when only images from April were employed but increased to 6.61 when the time series length was two months. However, with the additional inclusion of images from October and November and the phenological metrics, the 
separability did not increase substantially. When images from April to September were used, the $\mathrm{J}_{\mathrm{BH}}$ was 8.43, and when images from all eight months were used, $\mathrm{J}_{\mathrm{BH}}$ increased only slightly to 8.6. In addition, the separability increased substantial when a few features were used for each time series, but did not increase substantial when more features were employed. For example, JBH increased from 2.2 to 7.2 when the number of features increased from 1 to 24 for the April-August time series, but only increased to 8.4 when all 171 features in this period were used.

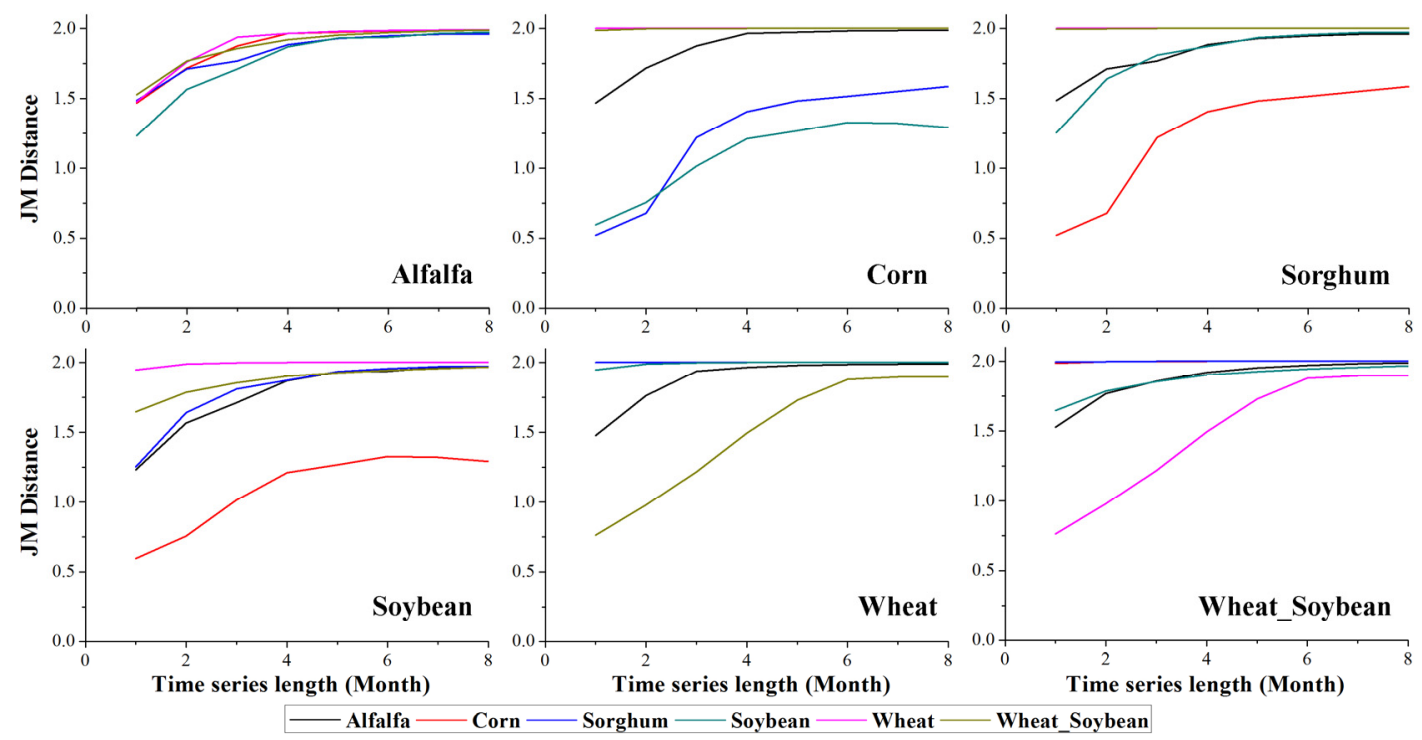

Figure 6. JM distance values for all crop pair comparisons with different time series lengths using training samples from Kansas.

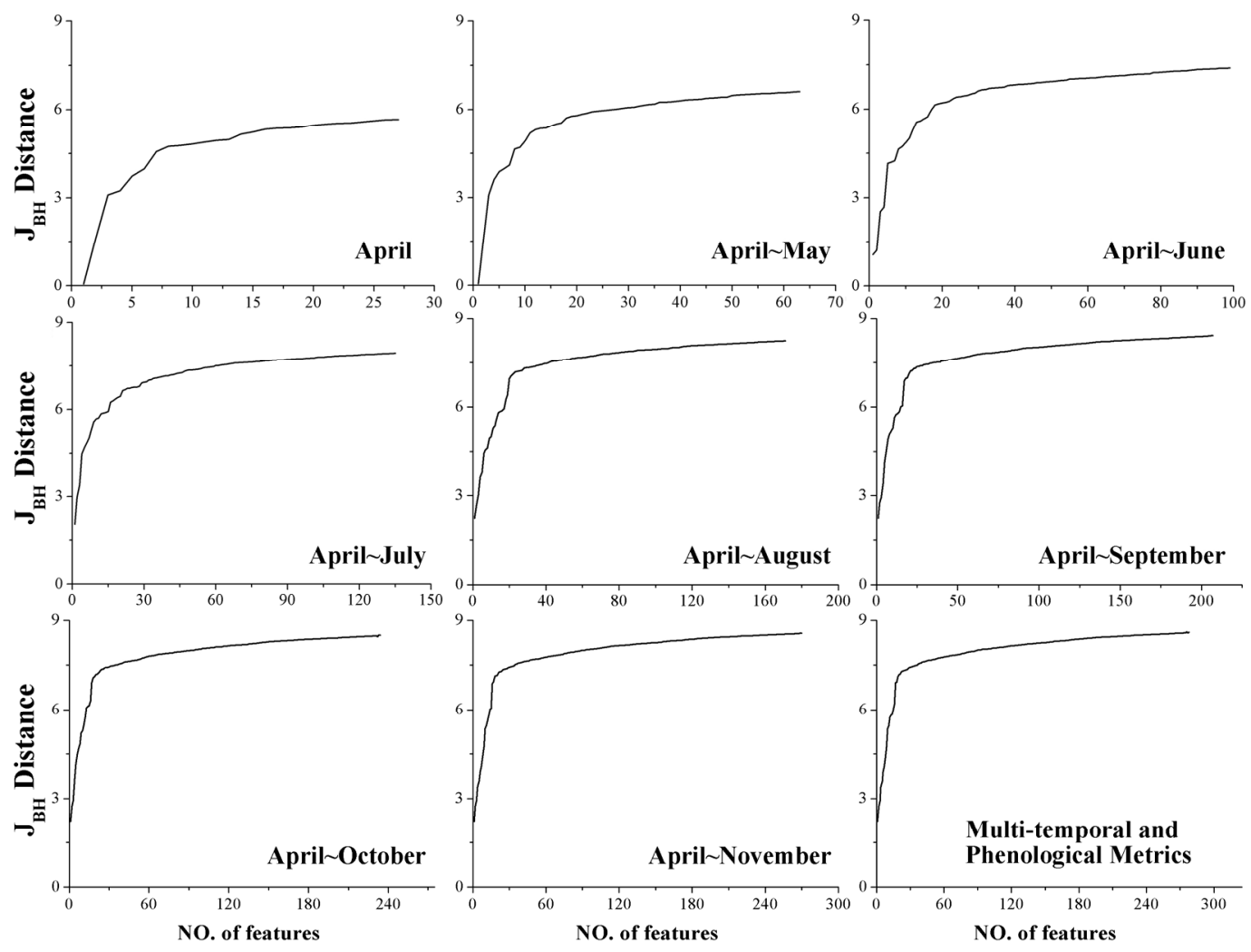

Figure 7. $\mathrm{J}_{\mathrm{BH}}$ obtained from training samples using the different input features suggested by the RF importance scores for different time series lengths. 


\subsection{Classification Accuracy}

The influence of the time series length and the number of features on the classification accuracy was shown in Figure 8. For each time series, the overall classification accuracy increased with the number of features used for classification until a saturation point was reached, after which the accuracy did not increase further. For example, the overall accuracy increased to a saturation point at 14 features (72.18\%) and 23 features $(88.56 \%)$ for the April and the April-November time series, respectively. Among the different time series lengths, combinations of only one or two months could not achieve a classification accuracy of more than $80 \%$. For the April time series, the maximum overall accuracy was $72.77 \%$; and when the time series length increased to two months (April-May), the maximum overall accuracy was $77.83 \%$. When the time series was longer than five months, the overall accuracy also reached a saturation point. The maximum overall accuracy increased from $88.45 \%$ to just $88.81 \%$ when the time series length was increased from five months (April-August) to six months (April-September).
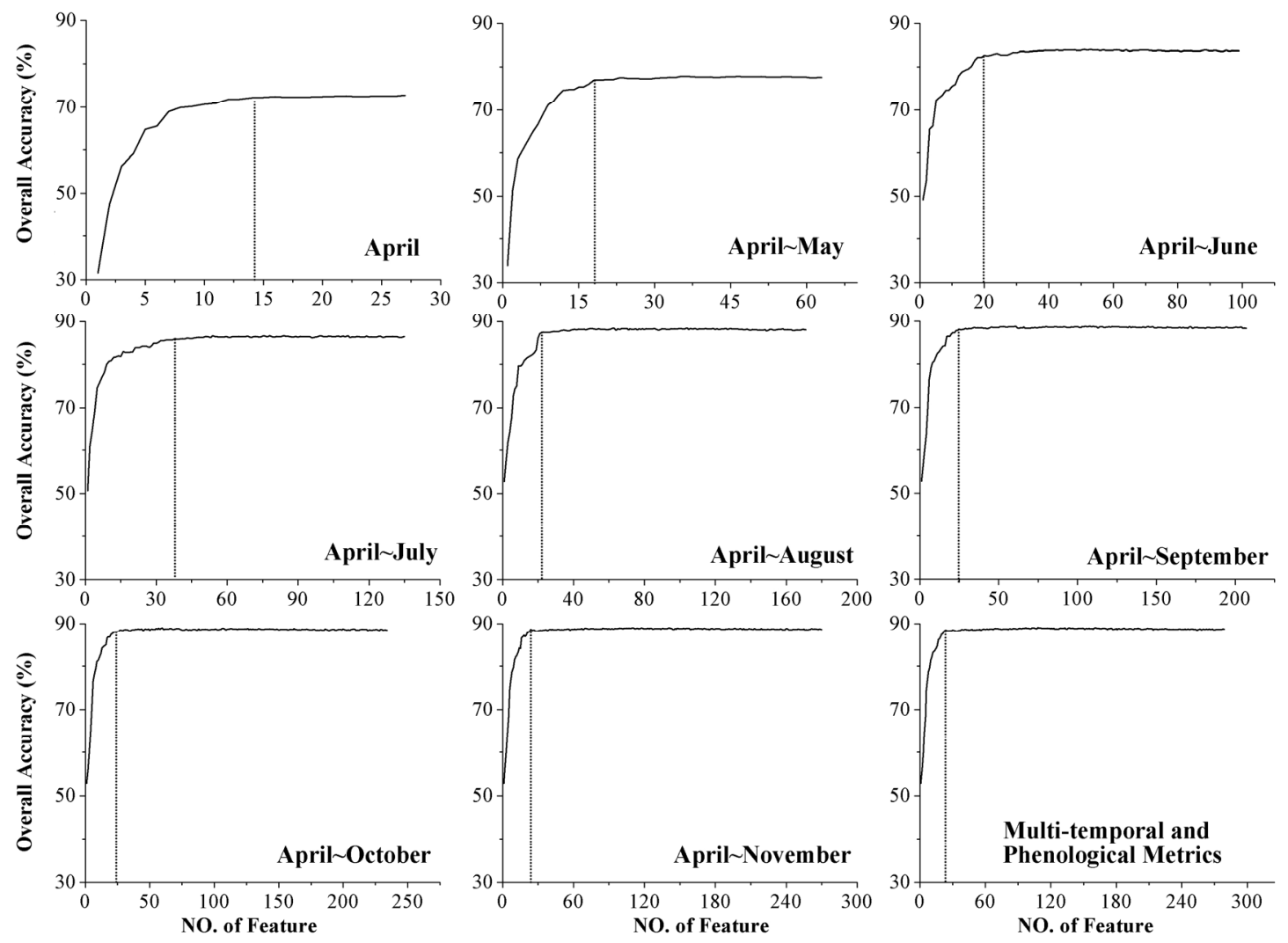

Figure 8. Overall accuracy (\%) of validation samples found from the RF algorithm using the different input features suggested by the importance score for different time series lengths. Only the average overall accuracy is shown in this figure because the standard deviation of the 10 -model run is approximately $0.1 \%$. The dotted line shows the saturation point for each time series length.

The producer's and user's accuracies achieved from the different time series are shown in Table 4. When the time series was short (one month or two months), wheat had relatively high producer's and user's accuracies ( $\mathrm{PA}=96.75 \%$ and $\mathrm{UA}=88.03 \%)$, while both producer's and user's accuracies for other crops were less than $70 \%$ in most cases. In addition, the accuracies increased with the time series 
length and remained stable when the time series was longer than five months, which was consistent with the trend of the overall accuracy. Among all the crop types, wheat had the highest classification accuracy $(\mathrm{UA}=95.58 \%$ and $\mathrm{PA}=95.39 \%)$ for the five-month time series. Alfalfa had high UA (92.13\%) but relatively low PA (85.56\%). Although the accuracies were relatively low compared with those for the other crops, the three summer crops were distinguishable because all PA and UA values were above $80 \%$, which was consistent with the separability of these three crops discussed in Section 4.2.

Table 4. Producer's and user's accuracies obtained from the different time series for each crop.

\begin{tabular}{ccccccc}
\hline & Alfalfa & Corn & Sorghum & Soybean & Wheat & Wheat-Soybean \\
\hline & PA/UA & PA/UA & PA/UA & PA/UA & PA/UA & PA/UA \\
\hline April & $62.2 \% / 75.9 \%$ & $70.0 \% / 63.1 \%$ & $55.5 \% / 67.2 \%$ & $65.7 \% / 61.3 \%$ & $96.8 \% / 88.0 \%$ & $56.1 \% / 84.2 \%$ \\
April $\sim$ May & $71.3 \% / 87.3 \%$ & $79.3 \% / 66.4 \%$ & $62.6 \% / 74.5 \%$ & $66.5 \% / 70.9 \%$ & $97.8 \% / 88.9 \%$ & $58.4 \% / 87.3 \%$ \\
April $\sim$ June & $75.4 \% / 92.4 \%$ & $83.9 \% / 78.5 \%$ & $79.8 \% / 81.8 \%$ & $75.8 \% / 74.8 \%$ & $99.1 \% / 91.3 \%$ & $61.1 \% / 87.5 \%$ \\
April $\sim$ July & $81.3 \% / 92.5 \%$ & $86.1 \% / 82.0 \%$ & $82.3 \% / 84.0 \%$ & $78.8 \% / 78.7 \%$ & $99.6 \% / 93.6 \%$ & $70.3 \% / 89.8 \%$ \\
April $\sim$ August & $85.6 \% / 92.1 \%$ & $86.0 \% / 83.2 \%$ & $83.7 \% / 87.1 \%$ & $81.8 \% / 80.2 \%$ & $99.6 \% / 95.4 \%$ & $76.9 \% / 91.1 \%$ \\
April $\sim$ September & $85.4 \% / 92.3 \%$ & $85.8 \% / 83.4 \%$ & $84.1 \% / 87.3 \%$ & $82.1 \% / 79.7 \%$ & $99.5 \% / 96.6 \%$ & $80.8 \% / 90.8 \%$ \\
April $\sim$ October & $85.2 \% / 92.1 \%$ & $86.4 \% / 83.6 \%$ & $83.9 \% / 87.5 \%$ & $82.1 \% / 79.9 \%$ & $99.5 \% / 96.7 \%$ & $81.0 \% / 90.5 \%$ \\
April $\sim$ November & $85.7 \% / 93.0 \%$ & $85.7 \% / 84.5 \%$ & $84.5 \% / 87.1 \%$ & $82.8 \% / 79.8 \%$ & $99.4 \% / 96.7 \%$ & $81.0 \% / 91.0 \%$ \\
Add Phe & $85.6 \% / 93.3 \%$ & $85.9 \% / 84.2 \%$ & $84.2 \% / 87.5 \%$ & $83.2 \% / 79.6 \%$ & $99.5 \% / 96.5 \%$ & $81.0 \% / 91.1 \%$ \\
\hline
\end{tabular}

\subsection{Classification Certainty}

The influences of the time series length and the number of features on the average classification certainty are shown in Figure 9. When only one feature was used for classification, the classification certainty was relatively high (nearly 0.9 in most cases) with a low classification accuracy (less than $60 \%$ ). Then, the certainty decreased substantially until reaching a minimum. After this point, the certainty began to increase until it reached a saturation point, and then remained generally stable at, for example, nine features (certainty $=0.68$ ) and 21 features (certainty $=0.81$ ) for the April and April-August time series, respectively. Similarly, the stable classification certainties increased with augmentation of the time series length. Additionally, when the time series was longer than five months, the certainty did not continue to increase. For example, from the three-month (April-June) to the four-month (April-July) time series, the stable certainty increased from 0.71 to 0.78 ; whereas from the five-month time series (April-August) to the six-month (April-September) series, stable certainty remained unchanged $(0.81)$.

The distributions of certainty for correctly and wrongly classified validation samples are shown in Figure 10. For the correctly labeled samples, certainty was mainly in the range $[0.8,1]$; for the wrongly labeled samples, certainty was mainly in the range $[0.4,0.8]$. In addition, when the time series was relatively short, the certainty of several correctly classified samples was low. For example, in the April time series, the certainties of nearly $20 \%$ of the correctly labeled samples were in the range $[0.4,0.6]$, and the certainties of only about $30 \%$ of the correctly labeled samples were in the range $[0.8,1]$. However, when the time series was longer than five months, more than $60 \%$ of the validation samples were correctly labeled with high certainty (between $[0.8,1]$ ). 

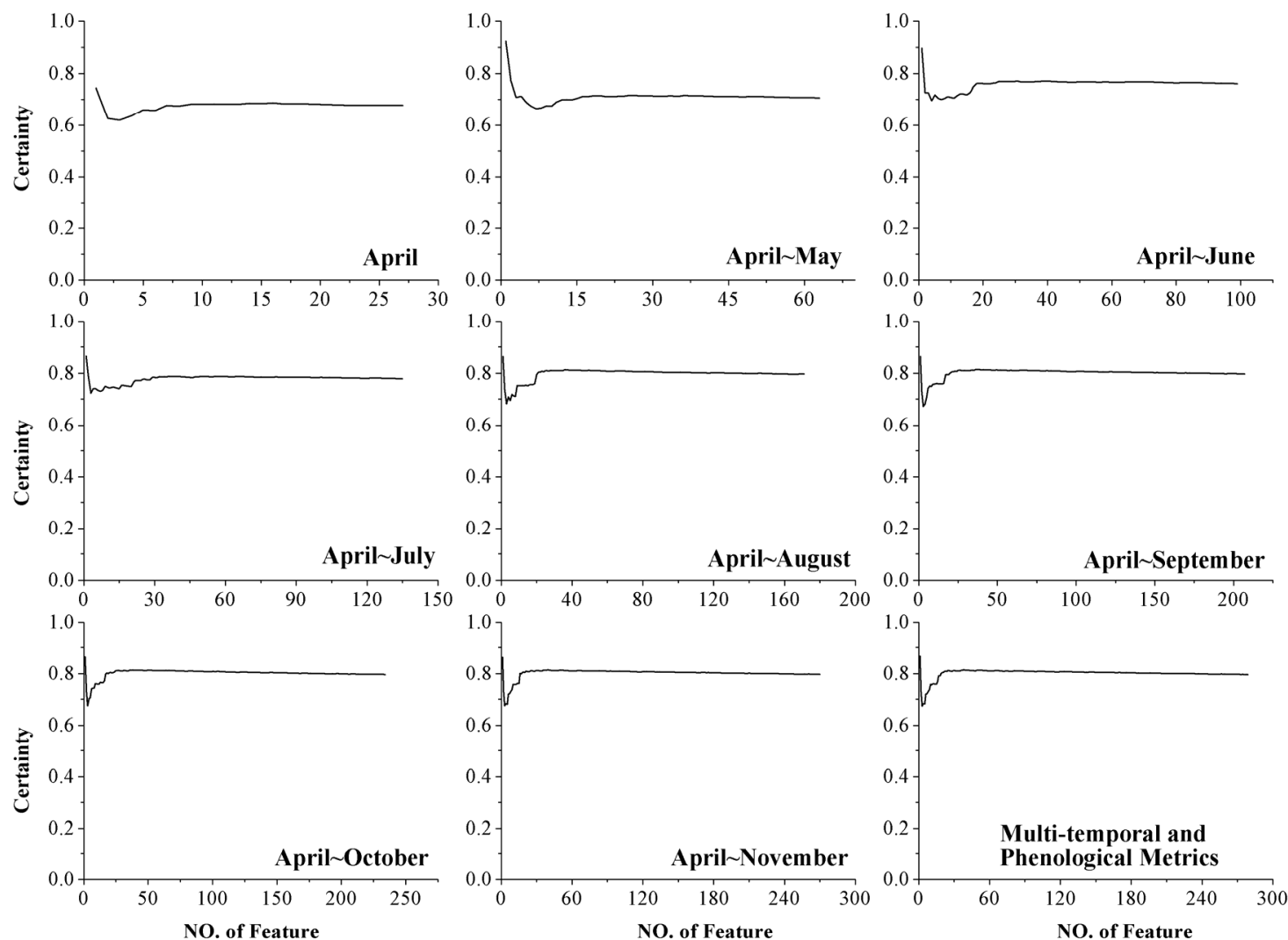

Figure 9. Classification certainty of validation samples derived from the RF algorithm using the different input features suggested by the importance score for different time series lengths.
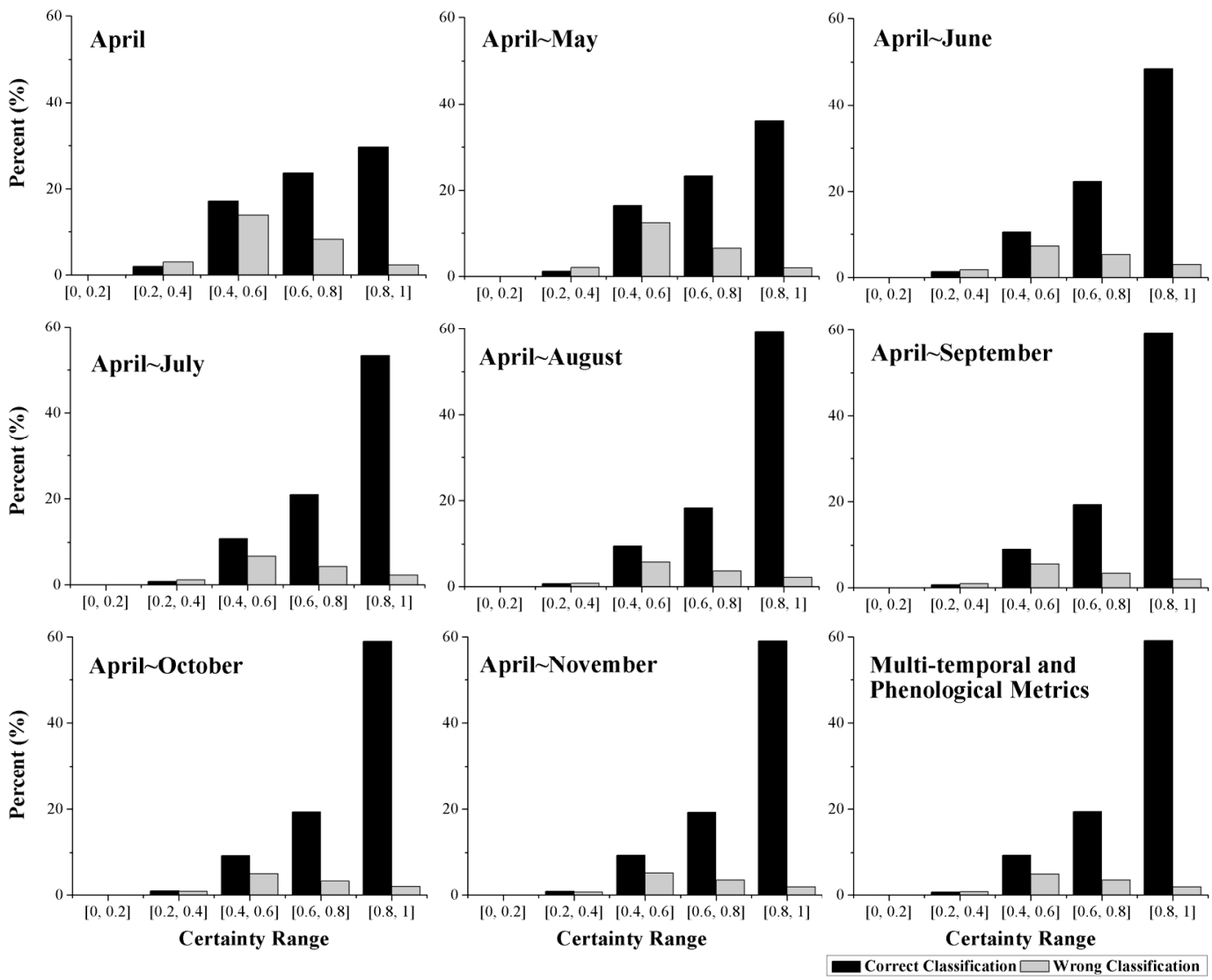

Figure 10. Frequency distributions of classification certainties for correctly and wrongly classified validation samples. 


\section{Discussion}

In this study, image time series of different lengths were used to identify crop types, and all three measurements (crop separability, classification accuracy, and certainty) showed that the five-month time series has the potential to classify the crops in the study area accurately, and that longer time series cannot improve the classification result. However, the crop types determine the optimal time series length. In Kansas, the dominant crops are wheat, alfalfa, corn, sorghum, and soybean. The winter crop, wheat, is separable from all the other crops when the time series length is only one month; alfalfa also shows high separability during the early growing season, when the summer crops have not yet developed. For the three summer crops, corn, sorghum, and soybean, the time periods of different emergence rate contribute most substantially to the high separability.

Previous studies have shown that rather than using the entire growing season, images of several optimal time periods can achieve high classification accuracy [14,17]. Additionally, according to [16], the most separable time periods for the summer crops in Kansas are during the initial spring green-up phase and/or the late senescence phase in June and early October, respectively. Although the short time series in this research (such as the April-August time series) cover only a part of the optimal time periods for crop identification, they still have the potential to correctly classify crops. More importantly, the earlier classification using these short periods makes the crop map more valuable.

For each time series, separability, classification accuracy, and certainty can be achieved using a portion of the features similar to using all the features available for that time series. Low et al [24] sorted features by their RF importance score and used SVM to detect the relationship between classification accuracy and the number of features exploited. The accuracy reached a peak when a fraction of the available features was employed, and the accuracy declined substantially with the addition of other features. The same situation has been observed in SVM classification using hyper-spectral data [48]. In the presented research, the RF algorithm was employed to classify the crop types, and the classification accuracy and certainty remained stable when additional features were used, which is also consistent with the findings of [24] that the RF algorithm was less affected by the number of features than SVM.

In this study, we calculated all month-by-month crop pair comparisons using both multi-spectral data and indices (NDVI and NDWI). Compared with previous research using only NDVI and EVI time series [16], the separability of crop pairs in this research is relatively high. For example, the JM distance between corn and sorghum was more than 1 in July. This relatively high separability is because of several factors. First, the temporal unit in this research is one month, with three or four time periods in each month. However, the separability analysis of [16] is based on the 16-day NDVI and EVI, and the temporal unit is the single time period. Second, in addition to NDVI, both multi-spectral data and NDWI were included in this research. Although NDVI features comprised the majority of the top ten features selected for time series longer than five months, several multi-spectral and NDWI features, such as NDWI_D12 and B6D19 (Figure 3), were also selected as key features, and these features increased the separability when identifying crops over short time series.

The phenological metrics features were not selected for the top ten features for crop identification (Figure 3), which indicates that phenological metrics may not classify crops as good as the other features. This is mainly because of phenological character variations in crop development schedules due to local weather conditions and farm management. For example, the recommended planting date for corn varies 
by nearly one month from southeast to northwest Kansas. Another complicating factor is that the phenological metrics are sensitive to the signal noise introduced by pre-crop vegetation. This pre-crop vegetation mainly consists of weeds and "volunteer crops" (in particular, winter wheat), and can lead to a misleading early estimation of the green-up onset of the crops. As a result, estimates for several phenological metrics, such as SOST, SOSN, and DOS, are prone to errors and inconsistencies [49]. Moreover, several other phenological features, such as EOST, EOSN, and DOS, can only be acquired after harvest, which may delay the completion of the crop map.

When using short time series to identify the crops, both the classification accuracy and certainty were low (Figure 10), and even several correctly classified samples had low certainty (between 0.4 and 0.6). This was because of the low separability among the different crops when the length of the time series was one or two months (Figure 5). The classification certainty increased with the time series length, but several correctly labeled validation samples still had low classification certainty (between 0.4 and 0.6 ). Figure 11 shows the average probability of validation samples for each crop type within different certainty ranges. For corn samples, the low certainty samples have high probability for soybean and sorghum. Similarly, the sorghum samples with low certainty also have relatively high probabilities for corn and soybean, which is consistent with the low JM distance among these three crops (Figure 4). Generally, low separability leads to low classification certainty.
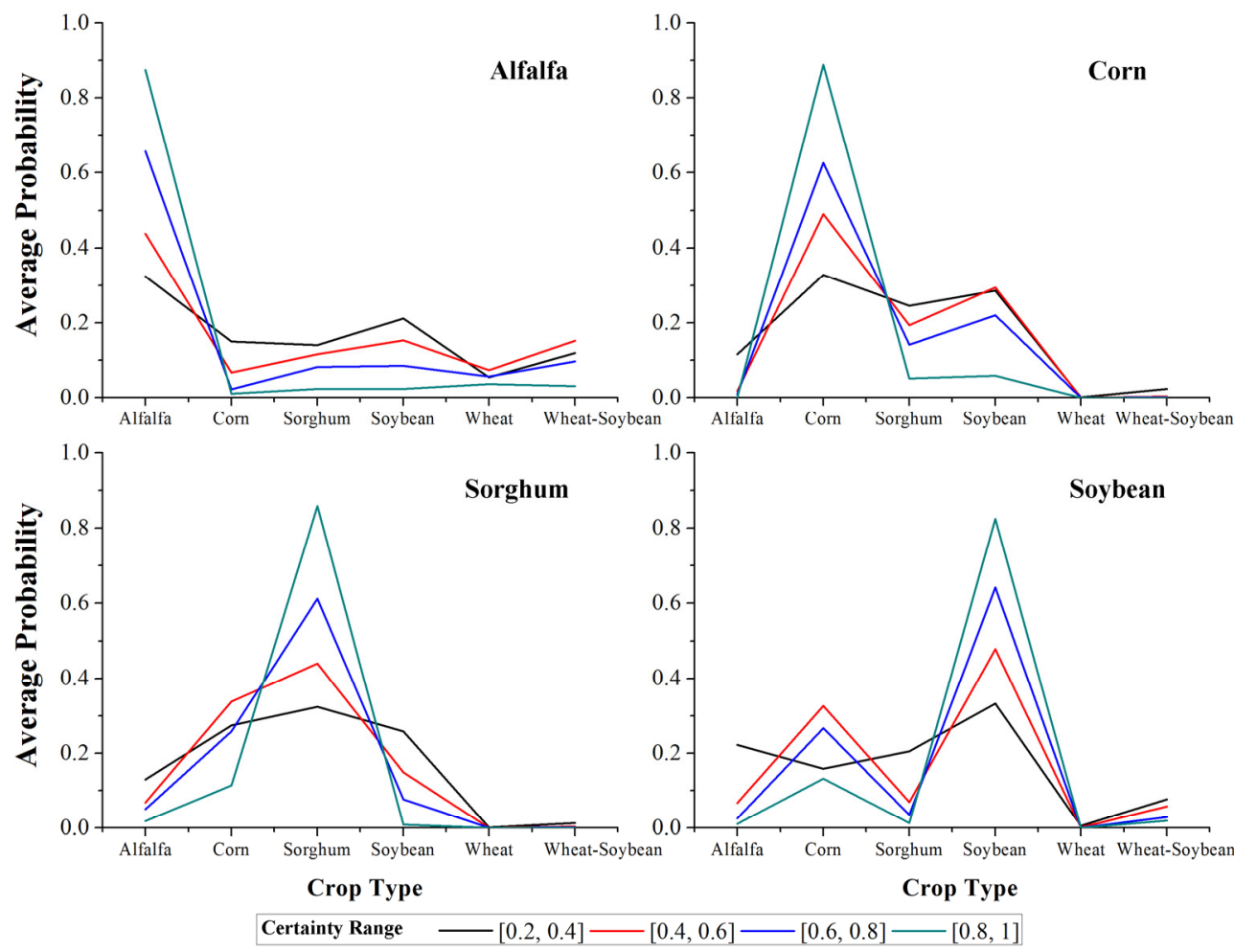

Figure 11. Average probability for the validation samples for each crop type. Different line types indicate different levels of uncertainty. All 270 features of the eight-month time series were used to calculate the probability in Figure 10.

CDL data were used as ground reference data in this research, which may introduce some uncertainty regarding our conclusions. Some misclassification of CDL data may lead to variations in a crop's features (such as the NDVI time series), and the underestimation of the separability between several 
crops (such as alfalfa and soybean during April and May). Another complication is that the use of CDL as ground reference data may lead to overly optimistic classification accuracies in this research. This is because both MODIS and Landsat (the basis for CDL) data are dependent on similar local atmospheric and ground conditions. The reflectance from the two sensors may therefore correlate to some extent during the crop-growing season. As a result, the reported accuracy of this research is likely overstated to some degree. Additionally, we defined $80 \%$ as the threshold for a 'pure' pixel to increase the number of reference samples, but the relatively heterogeneous pixels may be a limiting factor for this research.

\section{Conclusion}

In this study, we investigated the influence of the time series length on crop identification using 8-day composite MODIS 500-m reflectance data (MOD09A1) in Kansas, USA, with CDL data as ground reference data. The main conclusions are as follows.

1. The augmentation of the time series length can improve crop classification because the separability among different crops, the classification accuracy, and the certainty are increased. In addition, the five-month time series (April to August) was the optimal time series for identifying crops in Kansas because longer time series cannot improve the classification performance (accuracy and certainty). The result also indicated that rather than the entire growing season, relatively short time series have the potential to accurately classify crops.

2. For each time series used in this research, additional features improved the classification, as measured by higher separability, classification accuracy, and certainty. Additionally, a portion of these features (such as the first 23 features during the April-November time series) was sufficient to classify the crops accurately, and adding more features after this point had no significant positive effect on crop identification.

3. Among the features used in this research, NDVI was the most important feature, as shown by the fact that NDVI features comprised the majority of the top ten features during the eight-month time series (April-November). In addition, the water content index (NDWI) and multi-spectral band data also contributed to distinguishing between the crop types. The phenological metrics features had a relatively low importance and were not selected as the most important features. Moreover, several phenological features, such as EOST and EOSN, can only be obtained after harvest and therefore, cannot contribute to early crop identification using short time series.

4. The RF algorithm was used in this research to calculate the importance score, classify the crops, and obtain the classification certainty. When the time series was longer than five months, little change was seen among the top ten features. In addition, the classification accuracy and certainty remained stable when additional features were employed. These results indicate that the RF algorithm is a suitable algorithm for selecting features and classifying crops using a large volume of data.

In this research, we investigated the potential of using multiple features, including NDVI, NDWI, and multi-spectral band data, to classify crops in short time series, which could contribute to early crop 
mapping over a large area. After all, crop separability and optimal crop discriminating periods are determined by the crop type. Therefore, more work is needed to evaluate the contributions of different features to identifying specific crops using relatively short time series in other study areas.

\section{Appendix}

Table A1. Relationship between dates and months in this research.

\begin{tabular}{|c|c|c|c|c|}
\hline Month & Time Period in This Study & Date Flag & $\begin{array}{c}\text { Corresponding } \\
\text { Day of Year (DOY) }\end{array}$ & Date \\
\hline \multirow{3}{*}{ April } & 1 & 097 & 097-104 & 7 April-14 April \\
\hline & 2 & 105 & $105-112$ & 15 April-22 April \\
\hline & 3 & 113 & $113-120$ & 23 April-30 April \\
\hline \multirow{4}{*}{ May } & 4 & 121 & $121-128$ & 1 May-8 May \\
\hline & 5 & 129 & $129-136$ & 9 May-16 May \\
\hline & 6 & 137 & $137-144$ & 17 May-24 May \\
\hline & 7 & 145 & $145-152$ & 25 May-1 June \\
\hline \multirow[t]{4}{*}{ June } & 8 & 153 & $153-160$ & 2 June-9 June \\
\hline & 9 & 161 & $161-168$ & 10 June-17 June \\
\hline & 10 & 169 & $169-176$ & 18 June-25 June \\
\hline & 11 & 177 & $177-184$ & 26 June-3 July \\
\hline \multirow{4}{*}{ July } & 12 & 185 & $185-192$ & 4 July-11 July \\
\hline & 13 & 193 & $193-200$ & 12 July-19 July \\
\hline & 14 & 201 & $201-208$ & 20 July-27 July \\
\hline & 15 & 209 & $209-216$ & 28 July-4 August \\
\hline \multirow{4}{*}{ August } & 16 & 217 & $217-224$ & 5 August-12 August \\
\hline & 17 & 225 & $225-232$ & 13 August-20 August \\
\hline & 18 & 233 & $233-240$ & 21 August-28 August \\
\hline & 19 & 241 & $241-248$ & 29 August-5 September \\
\hline \multirow{3}{*}{ September } & 20 & 249 & $249-256$ & 6 September-13 September \\
\hline & 21 & 257 & $257-264$ & 14 September-21 September \\
\hline & 22 & 265 & $265-272$ & 22 September-29 September \\
\hline \multirow{4}{*}{ October } & 23 & 273 & $273-280$ & 30 September-7 October \\
\hline & 24 & 281 & $281-288$ & 8 October-15 October \\
\hline & 25 & 289 & $289-296$ & 16 October-23 October \\
\hline & 26 & 297 & 297-304 & 24 October-31 October \\
\hline \multirow{4}{*}{ November } & 27 & 305 & $305-312$ & 1 November- 8 November \\
\hline & 28 & 313 & $313-320$ & 9 November-16 November \\
\hline & 29 & 321 & $321-328$ & 17 November-24 November \\
\hline & 30 & 329 & $329-337$ & 25 November-2 December \\
\hline
\end{tabular}

\section{Acknowledgement}

This work was supported by the National Natural Science Foundation of China (41371416), (41371358) and National Science and Technology Major Project (14CNIC-032079-32-02). Moreover, we would thank the reviewers and editors for the constructive suggestions. In addition, the authors thank the NASS for providing the CDL data for free. 


\section{Author Contributions}

Pengyu Hao designed the experiments, processed the data and wrote the paper. Yulin Zhan, Li Wang, Zheng Niu and Muhammad Shakir contributed important ideas and considerations

\section{Conflicts of Interest}

The authors declare no conflict of interest.

\section{References}

1. Vintrou, E.; Ienco, D.; Begue, A.; Teisseire, M. Data mining, a promising tool for large-area cropland mapping. IEEE J. Sel. Top. Appl. Earth Obs. Remote Sens. 2013, 6, 2132-2138.

2. Potgieter, A.B.; Lawson, K.; Huete, A.R. Determining crop acreage estimates for specific winter crops using shape attributes from sequential MODIS imagery. Int. J. Appl. Earth Obs. Geoinf. 2013, 23, 254-263.

3. Potgieter, A.B.; Apan, A.; Hammer, G.; Dunn, P. Early-season crop area estimates for winter crops in NE Australia using MODIS satellite imagery. ISPRS J. Photogramm. Remote Sens. 2010, 65, 380-387.

4. Howard, D.M.; Wylie, B.K. Annual crop type classification of the US Great Plains for 2000 to 2011. Photogramm. Eng. Remote Sens. 2014, 80, 537-549.

5. Atzberger, C. Advances in remote sensing of agriculture: Context description, existing operational monitoring systems and major information needs. Remote Sens. 2013, 5, 949-981.

6. Zhang, J.H.; Feng, L.L.; Yao, F.M. Improved maize cultivated area estimation over a large scale combining MODIS-EVI time series data and crop phenological information. ISPRS J. Photogramm. Remote Sens. 2014, 94, 102-113.

7. Senturk, S.; Sertel, E.; Kaya, S.; Vineyards mapping using object based analysis. In Proceedings of 2013 Second International Conference on Agro-Geoinformatics (Agro-Geoinformatics), Fairfax, VA, USA, 12-16 August 2013.

8. Amoros-Lopez, J.; Gomez-Chova, L.; Alonso, L.; Guanter, L.; Zurita-Milla, R.; Moreno, J.; Camps-Valls, G. Multitemporal fusion of Landsat/TM and ENVISAT/MERIS for crop monitoring. Int. J. Appl. Earth Obs. Geoinf. 2013, 23, 132-141.

9. Kuenzer, C.; Knauer, K. Remote sensing of rice crop areas. Int. J. Remote Sens. 2013, 34, 2101-2139.

10. Cable, J.W.; Kovacs, J.M.; Shang, J.L.; Jiao, X.F. Multi-temporal polarimetric Radarsat-2 for land cover monitoring in northeastern Ontario, Canada. Remote Sens. 2014, 6, 2372-2392.

11. Wang, D.; Lin, H.; Chen, J.S.; Zhang, Y.Z.; Zeng, Q.W. Application of multi-temporal ENVISAT ASAR data to agricultural area mapping in the Pearl River Delta. Int. J. Remote Sens. 2010, 31, $1555-1572$.

12. Jia, K.; Wu, B.; Li, Q. Crop classification using HJ satellite multispectral data in the North China Plain. J. Appl. Remote Sens. 2013, 7, 073576. 
13. Brown, J.C.; Kastens, J.H.; Coutinho, A.C.; Victoria, D.D.; Bishop, C.R. Classifying multiyear agricultural land use data from Mato Grosso using time-series MODIS vegetation index data. Remote Sens. Environ. 2013, 130, 39-50.

14. Murakami, T.; Ogawa, S.; Ishitsuka, N.; Kumagai, K.; Saito, G. Crop discrimination with multitemporal SPOT/HRV data in the Saga Plains, Japan. Int. J. Remote Sens. 2001, 22, 1335-1348.

15. Van Niel, T.G.; McVicar, T.R. Determining temporal windows for crop discrimination with remote sensing: A case study in south-eastern Australia. Comput. Electron. Agric. 2004, 45, 91-108.

16. Wardlow, B.D.; Egbert, S.L.; Kastens, J.H. Analysis of time-series MODIS $250 \mathrm{~m}$ vegetation index data for crop classification in the US Central Great Plains. Remote Sens. Environ. 2007, 108, 290-310.

17. Hao, P.; Wang;, L.; Niu; Z.; Aablikim;, A.; Huang;, N.; Xu;, S.; Chen;, F. The potential of time series merged from Landsat-5 tm and HJ-1 CCD for crop classification: A case study for Bole and Manas counties in Xinjiang, China. Remote Sens. 2014, 6, 7610-7631.

18. Gallego, J.; Craig, M.; Michaelsen, J.; Bossyns, B.; Fritz, S. Best practices for crop area estimation with remote sensing; European Commission Joint Research Centre: Ispra, Italy, 2010.

19. Zhou, F.Q.; Zhang, A.N.; Townley-Smith, L. A data mining approach for evaluation of optimal time-series of MODIS data for land cover mapping at a regional level. ISPRS J. Photogramm. Remote Sens. 2013, 84, 114-129.

20. Zhong, L.H.; Gong, P.; Biging, G.S. Phenology-based crop classification algorithm and its implications on agricultural water use assessments in California's Central Valley. Photogramm. Eng. Remote Sens. 2012, 78, 799-813.

21. Zhong, L.H.; Gong, P.; Biging, G.S. Efficient corn and soybean mapping with temporal extend ability: A multi-year experiment using Landsat imagery. Remote Sens. Environ. 2014, 140, 1-13.

22. Wardlow, B.D.; Egbert, S.L. A comparison of MODIS 250-m EVI and NDVI data for crop mapping: A case study for Southwest Kansas. Int. J. Remote Sens. 2010, 31, 805-830.

23. Da Silva, C.A.; Frank, T.; Rodrigues, T.C.S. Discrimination of soybean areas through images EVI/MODIS and analysis based on geo-object. Rev. Bras. Eng. Agric. Ambient. 2014, 18, 44-53.

24. Low, F.; Michel, U.; Dech, S.; Conrad, C. Impact of feature selection on the accuracy and spatial uncertainty of per-field crop classification using support vector machines. ISPRS J. Photogramm. Remote Sens. 2013, 85, 102-119.

25. Vieira, M.A.; Formaggio, A.R.; Renno, C.D.; Atzberger, C.; Aguiar, D.A.; Mello, M.P. Object based image analysis and data mining applied to a remotely sensed Landsat time-series to map sugarcane over large areas. Remote Sens. Environ. 2012, 123, 553-562.

26. Loosvelt, L.; Peters, J.; Skriver, H.; De Baets, B.; Verhoest, N.E.C. Impact of reducing polarimetric SAR input on the uncertainty of crop classifications based on the random forests algorithm. IEEE Trans. Geosci. Remote Sens. 2012, 50, 4185-4200.

27. Congalton, R.G. A review of assessing the accuracy of classifications of remotely sensed data. Remote Sens. Environ. 1991, 37, 35-46.

28. Bloch, I. Information combination operators for data fusion: A comparative review with classification. IEEE Trans. Syst. Man Cybern. Part A: Syst. Humans 1996, 26, 52-67.

29. Mountrakis, G.; Im, J.; Ogole, C. Support vector machines in remote sensing: A review. ISPRS J. Photogramm. Remote Sens. 2011, 66, 247-259.

30. Breiman, L. Random forests. Mach. Learn. 2001, 45, 5-32. 
31. Cropscape-Cropland Data Layer. Available online: http://nassgeodata.gmu.edu/CropScape/ (accessed on 02 December 2014).

32. Wardlow, B.D.; Egbert, S.L. Large-area crop mapping using time-series MODIS 250-m NDVI data: An assessment for the U.S. Central Great Plains. Remote Sens. Environ. 2008, 112, 1096-1116.

33. Masialeti, I.; Egbert, S.; Wardlow, B.D. A comparative analysis of phenological curves for major crops in Kansas. Gisci. Remote Sens. 2010, 47, 241-259.

34. Kansas crop planting guide. Available online: http://www.ksre.k-state.edu/bookstore/pubs/1818.pdf (accessed on 23 April 2015).

35. Land Processes Distributed Active Archive Center. Available online: http://lpdaac.usgs.gov/ (accessed on 23 April 2015).

36. Gao, B.C. NDWI-A normalized difference water index for remote sensing of vegetation liquid water from space. Remote Sens. Environ. 1996, 58, 257-266.

37. Viña, A.; Tuanmu, M.-N.; Xu, W.; Li, Y.; Qi, J.; Ouyang, Z.; Liu, J. Relationship between floristic similarity and vegetated land surface phenology: Implications for the synoptic monitoring of species diversity at broad geographic regions. Remote Sens. Environ. 2012, 121, 488-496.

38. Remote Sensing Phenology. Available online: http://phenology.cr.usgs.gov/ (accessed on 11 December 2014).

39. USDA National agricultural statistics service, 2013 Kansas cropland data layer. Available online: http://www.nass.usda.gov/research/Cropland/metadata/metadata_ks13.htm (accessed on 11 December 2014).

40. Surface Reflectance 8-Day L3 Global 500m. Available online: https://pdaac.usgs.gov/products/ MODIS_products_table/mod09a1 (accessed on 12 December 2014).

41. Rodriguez-Galiano, V.F.; Ghimire, B.; Rogan, J.; Chica-Olmo, M.; Rigol-Sanchez, J.P. An assessment of the effectiveness of a random forest classifier for land-cover classification. ISPRS J. Photogramm. Remote Sens. 2012, 67, 93-104.

42. Liaw, A.; Wiener, M. Randomforest: Breiman and Cutler's Random Forests for Classification and Regression. Available online: http://cran.r-project.org/web/packages/randomForest/index.html (accessed on 15 December 2014).

43. Loosvelt, L.; Peters, J.; Skriver, H.; Lievens, H.; Van Coillie, F.M.B.; De Baets, B.; Verhoest, N.E.C. Random forests as a tool for estimating uncertainty at pixel-level in SAR image classification. Int. J. Applied Earth Obs. Geoinf. 2012, 19, 173-184.

44. Van Niel, T.G.; McVicar, T.R.; Datt, B. On the relationship between training sample size and data dimensionality: Monte Carlo analysis of broadband multi-temporal classification. Remote Sens. Environ. 2005, 98, 468-480.

45. Adam, E.; Mutanga, O. Spectral discrimination of papyrus vegetation (Cyperus Papyrus L.) in swamp wetlands using field spectrometry. ISPRS J. Photogramm. Remote Sens. 2009, 64, 612-620.

46. Bruzzone, L.; Roli, F.; Serpico, S.B. An extension of the Jeffreys-Matusita distance to multiclass cases for feature selection. IEEE Trans. Geosci. Remote Sens. 1995, 33, 1318-1321.

47. Huang, X.; Zhang, L. An SVM ensemble approach combining spectral, structural, and semantic features for the classification of high-resolution remotely sensed imagery. IEEE Trans. Geosci. Remote Sens. 2013, 51, 257-272. 
48. Pal, M.; Foody, G.M. Feature selection for classification of hyperspectral data by SVM. IEEE Trans. Geosci. Remote Sens. 2010, 48, 2297-2307.

49. Wardlow, B.D.; Kastens, J.H.; Egbert, S.L. Using USDA crop progress data for the evaluation of greenup onset date calculated from MODIS 250-meter data. Photogramm. Eng. Remote Sens. 2006, $72,1225-1234$.

(C) 2015 by the authors; licensee MDPI, Basel, Switzerland. This article is an open access article distributed under the terms and conditions of the Creative Commons Attribution license (http://creativecommons.org/licenses/by/4.0/). 